\title{
Urban Drifting: An Approach to City Comprehension and Mapping
}

\author{
Alexandros Daniilidis ${ }^{\mathrm{a}}$
}

\begin{abstract}
Iain Sinclair, in his Lights Out for the Territory (1997) declared that "walking is the best way to explore and exploit the city". But what exactly is that we are looking for in our contemporary cities? And how can walking contribute in tracing (explore) and therefore mapping (exploit) all those elements or situations that we seek for? Urban space is constantly mutating. Our experience of space as a practiced place changes gradually as the surrounding urban environment evolves around us. Amidst "sterile" private spaces and misleading billboards, the neo-urban walker drifts through the city in search for the peculiar, the original, the intriguing, and the fringe. An urban journey/drifting starts and ends without any predefined plan in mind, while remaining alert and receptive to all incentives given by the practiced urban locus (audio, visual, olfactory, and psychological incentives). Originating from the post-Romantic English writers and the mid-nineteenth century Parisian flâneur, urban drifting has been practiced in multiple ways with different outcomes, but yet highly contributory in the depiction and specific mapping of our urban environment. This paper attempts to investigate the roots of urban drifting, its evolution, and its potential utility as a spatial practice in visual arts, architecture, and mapping.
\end{abstract}

\section{Keywords}

Spatial practice, derive, city mapping, walking

Cities are complex, multi-layered, and artificial environments. A big interactive "database" of sounds, smells, images, faces, ideas, and notions, is dispersed throughout smaller parts which all together converge in forming the "urban puzzle", the city. Each and every one of these places can attract or repel us by emitting a psychologically warm or cold, friendly or hostile, interesting or simply indifferent feeling in a way that can be recorded and thus mapped. However all these notions and "clues" that describe the city and its components are not always apparent and require additional skills and techniques in order to be traced. We need to discover or rediscover ways and methods to fully understand and depict our cities in order to preserve their originality and these characteristics that constitute them are important to their inhabitants.
Urban drifting can be used as an experimental way of recording and mapping all these data that enhance an area with a unique and distinct "aura".

Urban drifting is walking. Walking within urban environments (cities, towns, and metropolises) without any particular destination or predefined plan in mind. Feeling - or rather experiencing - the stimulis given by the urban ambiance, varying from visual incentives (built, tangible environment) to invisible olfactory flows and sonant fluctuations (smellscape/soundscape). Interpreting the notions and

aUniversity of Brighton, Brighton, UK

\section{Correspondent Author:}

Alexandros Daniilidis, 9 Kingscote way, BN1 4GJ, Brighton, UK 
the relationships formed within the urban web while being unprejudiced and receptive to situations and paradoxes by all means. Discovering the dynamics created by the urban flow, the hidden history of the surroundings, the uncharted paths, obscure stories, and eventually the existing interrelationships among different parts of the city. Essentially, urban drifting — strolling, wandering, and straying - is the process of being part of an urban environment through long walks or detours, with an ulterior aim to comprehend the specific urban locus and all its characteristics that render it a site of architectural, artistic, political, and social interest. Urban drifting is "urban deviation", a subversive process of urban walking that re-establishes the sense of "spirit of place" (genius loci) and our experience of familiar surroundings.

\section{MODERNISTIC URBAN DIARIES: SURREALISM AND THE ART OF FLÂNERIE}

The crowd is his element, as the air is that of birds and water of fishes. His passion and his profession are to become one flesh with the crowd. For the perfect flâneur, for the passionate spectator, it is an immense joy to set up house in the heart of the multitude, amid the ebb and flow of movement, in the midst of the fugitive and the infinite. (Baudelaire 1964)

The origins of urban drifting as a conceptual spatial practice, can be traced back in mid/late nineteenth century Paris and the emergence of the flâneur ${ }^{1}$, the urban wanderer, or the "botanist of the sidewalk" (Saltz 2008) as Baudelaire described. An enigmatic but rather creative and radical figure was drifting through the elegant arcades of Paris and the notorious alleyways of East London, elevating his aimless strolls to an art form and a political statement. As a romantic lover of street life, the flâneur bounded up his fate with the fate of the city he inhabited. His "street journals" can provide useful information and historic facts about the city and its changing forms through time.
The primacy of the term can be granted to Charles Baudelaire with his essay The Painter of Modern Life (1863) where the term flâneur was first described as the symbol of modernity and the rise of the modern city. A few years earlier, on the other side of the English Channel, the descriptive word of E. A. Poe in his exceptional The Man of the Crowd (1840) introduced the first urban wanderer. The monomaniacal narrator's obsession with a certain character of the play, led him to places and situations of mid-nineteenth century London which, potentially, would never have experienced. E. A. Poe's character was somehow a flâneur, acting like a "detective" who was part of the hoi polloi and at the same time detached from it. As Franz Hessel noticed, "in order to engage flânerie, one must not have anything too definite in mind" ${ }^{2}$. In both occasions (Baudelaire, Poe), the flâneur was driven by chance, desire, advice, history, and his senses, rendering the conventional navigation tools inactive and opening up a new chapter in city's comprehension.

From the initial works of post-Romantic English writers like William Blake, Thomas De Quincey, or Robert Louis Stevenson, the city and its exploration and depiction had always been the main focus of Romantic/post-Romantic era literature. William Blake was a Londoner poet and writer and also an urban wanderer whose works described the real street life and the radicality (influenced by the French Revolution) of eighteenth century London (e.g. The Marriage of Heaven and Hell, 1793). Thomas De Quincey with his autobiographical piece Confessions of an English Opium Eater (1800) laid the foundations for the later movement of psychogeography and highly influenced the situationists of the 1950's. As he remarked, "I could almost have believed, at times, that I must be the first discoverer of some of these terrae incognitae (in the city of London)" (De Quincey 1997: 81). Robert Lewis Stevenson through his famous novel Dr. Jekyll and Mr. Hyde (1886) depicted the social differences of late nineteenth century London 
between the wealthy West London and the notorious degradation of East End. In an excerpt of his work, Stevenson described "the dismal quarter of Soho seen under these changing glimpses, (...) seemed, in the lawyer's eyes, like a district of some city in a nightmare"

The rise of the flâneur and his urban tales of city wandering in Paris and London may be described as a process of political awakening. His existence acts as an indication of the struggles that later generations of urban drifters (walkers) will have to face as the city is redeveloped in an increasingly hostile way to their activities. The redeveloping project led by Georges-Eugene Haussmann (1853-1870) changed significantly the French capital, giving way to large boulevards and grandiose facades over old and crowded neighbourhoods. In this new environment, the wanderer was soon engaged in an attempt to reclaim the streets and preserve the original history of the city. From Baudelaire and Benjamin to Breton and Aragon, Paris is represented as a place of growing unrest and radicalism. The notion of flanerie along with the Surrealist movement of early twentieth century, aimed to transform the experience of everyday life, challenge citizens' perspective of the city, and replace their dull urban existence with an appreciation of the extraordinary. Urban drifting as an activity, was established as a cultural and revolutionary act and became the ultimate methodological tool for the Situationist movement (1950s) in psychogeographical mapping and critic of the post-modern, capitalist city.

\section{PSYCHOGEOGRAPHY, SITUATIONIST INTERNATIONAL (SI), AND THE ART OF THE DÉRIVE}

"We are bored in the city, there is no longer a Temple of the Sun (...) we really have to strain to still discover mysteries on the sidewalk billboards, the latest state of humour and poetry" (Chtcheglov 1953).
The Situationist International (SI), which was formed in 1957 in Italy by eight delegates [former members of other radical movements like COBRA (COpenhagen, BRussels, Amsterdam) and Lettrist International] introduced a new Avant-Garde motivated by new revolutionary emotions, leaving its mark upon the Libertarian Left, the central European subcultures, and the events of May 1968 in France.

SI, under the decisive leadership of Guy Debord and other radical figures (Ivan Chtcheglov, Michèle Bernstein, Asger Jorn, and more), had as a theoretical goal the construction of situations, meaning the solid creation of momentary ambiances of life and their transformation into a superior passional quality with the ultimate goal to alter the perspective of modern urban life so that it could be transformed into a revolutionary potential. For Debord, psychogeography was the point where psychology and geography collide, a hermeneutic approach with which situationists aimed to record and interpret the emotional and behavioural impact of urban space upon individual consciousness. Someone might argue that psychogeography was the process of collecting civil experiences from the flip-side of modernization, an accusation of modern urban life, and a struggle to reassess and recreate the constantly deteriorating, fragmented urban space which was "abandoned for the suburbs, fragmented by urban renewal and tormented by the automobile" (Boyer 1995).

The act of urban drifting is a tool which was broadly used by the SI members as a radical process of engaging with and understanding the urban environment. Guy Debord introduced the term of dérive as "a mode of experimental behaviour linked to the conditions of urban society; a technique of transient passage through varied ambiances" ${ }^{4}$. Small, sensorial trips where "anything and nothing might happen" ${ }^{\prime \prime}$ cut across the division of urban space into work, rest, and leisure zones. By wandering about in the space of the city according to their own sense of time, those undertaking a dérive found other uses for 
space besides the predefined and functional ones.

By letting the city's atmospheres and stimulis of all kinds be their guides, the situationists hyper-sensitized themselves to the city's shapes, symbols, smells, and chance encounters. The act of walking - wandering was escalated to a higher level of consciousness, a subversive notion, and an indication of personality ready to be pulled in and "absorbed" by the flows and rhythms of the city. Tina Richardson likened dérive to an "active observation of present-day urban agglomerations" art of dérive is a constructive experimental behaviour that allows someone to rethink and understand the city and the way it should be. Psychogeographical interpretation is what someone gets from this urban walking - drifting; the manifestations of association, personality, sensorial effects, and generally the spirit of place (genius loci) are physically manifested in the street's architecture and the containing environment (see Figures 1 and 2).

\section{METHODOLOGICAL TOOL: URBAN DRIFTING AS A TEXTUAL AND VISUAL DATA GENERATOR}

So it began: my ritual of early morning long walks on Sundays in an emptied-out Los Angeles. Better at that early hour so that I could truly see it, the old bones, the dreams and find my place within them. These walks have been a way of slowing time down to better understand the city's layered story. (Lynell 2015: 19)

By urban drifting, we can obtain useful information from the "urban database" that can contribute in the visual and verbal representation of all these traces that form our cities. The major practice of urban drifting is walking with all our senses "alert", ready to encounter and record the paradox, the unprecedented, and the peculiar. The context of it can be separated in the following steps:

(1) Observation-recording;

(2) Data analysis;
(3) Evaluation;

(4) Conclusions/outcome(s)/mapping.

\section{ARCHITECTURAL/MAPPING PRACTICES: OBSERVATIONAL SKETCHING}

"Nothing is experienced by itself, but always in relation to its surroundings, the sequences of events leading up to it, the memory of past experiences" (Lynch 1960: 1).

Kevin Lynch, in his book The Image of the City (1960), argued that the public image of a city is consisted of numerous other individual images and thus, its "imageability" (Lynch 1960: 46) can be further classified into paths, edges, districts, nodes, and landmarks. Each one of these elements holds a significant role in the public image of the city as it is part of the tangible, evolving urban environment and hence, readable and recordable data. Urban drifting can be a useful tool in the hands of architects, city planners, or urban designers for a thorough recording, mapping, and eventually understanding of all of the above city elements. One essential method that can potentially derive from urban drifting/dérive is "observational sketching". By this, we mean a sequence of sketches drawn (either quick or more detailed) along the route of our walk that can depict on paper the revealed urban environment (see Figures 3, 4, and 5). The whole idea is also partly based on Gordon Cullen's theory of "serial vision". According to him, the scenery of the study area can be revealed to the walker "through a series of jerks (= sudden move) or revelations" [Cullen (1961) 1971: 9], while walking on a uniform speed through the urban environment (see Figure 6).

In her manual Drawing for Urban Design (2011), Lorraine Farrelly argued that in order to design within an urban environment, the existing context must be carefully studied and analysed as it can "reveal clues about the place that can be cultivated in ideas for the development of the city" (Farrelly 2011: 45). The very 


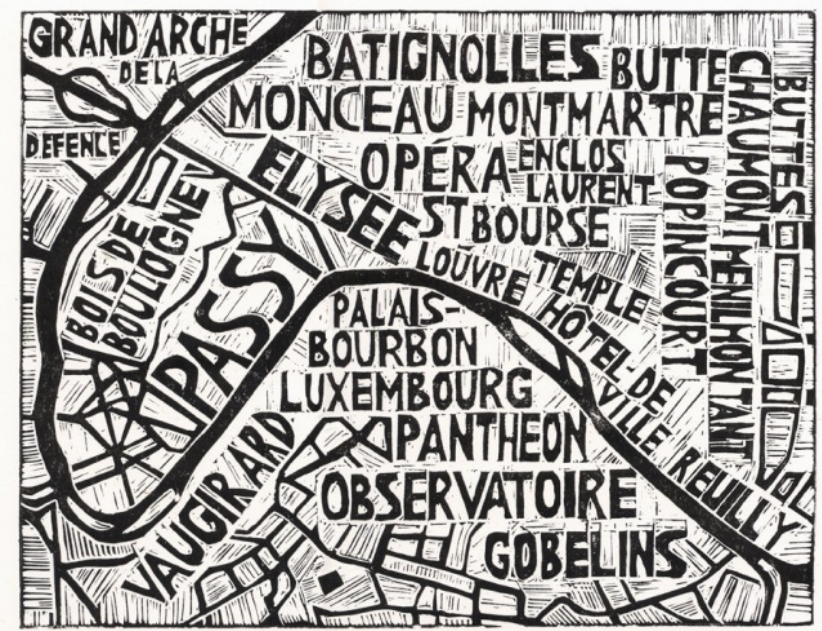

Figure 1. Abigail Daker, "Map of Paris' Arrondissements" (2013).

Notes: A psychogeographic map of Paris that divides the city into neighbourhoods only by using the predominant name for each specific area. The artist omits to provide any further information about the individual areas and thus, this map's utility lies upon the public's collective memory that accompanies each and every one of the arrondissements displayed.

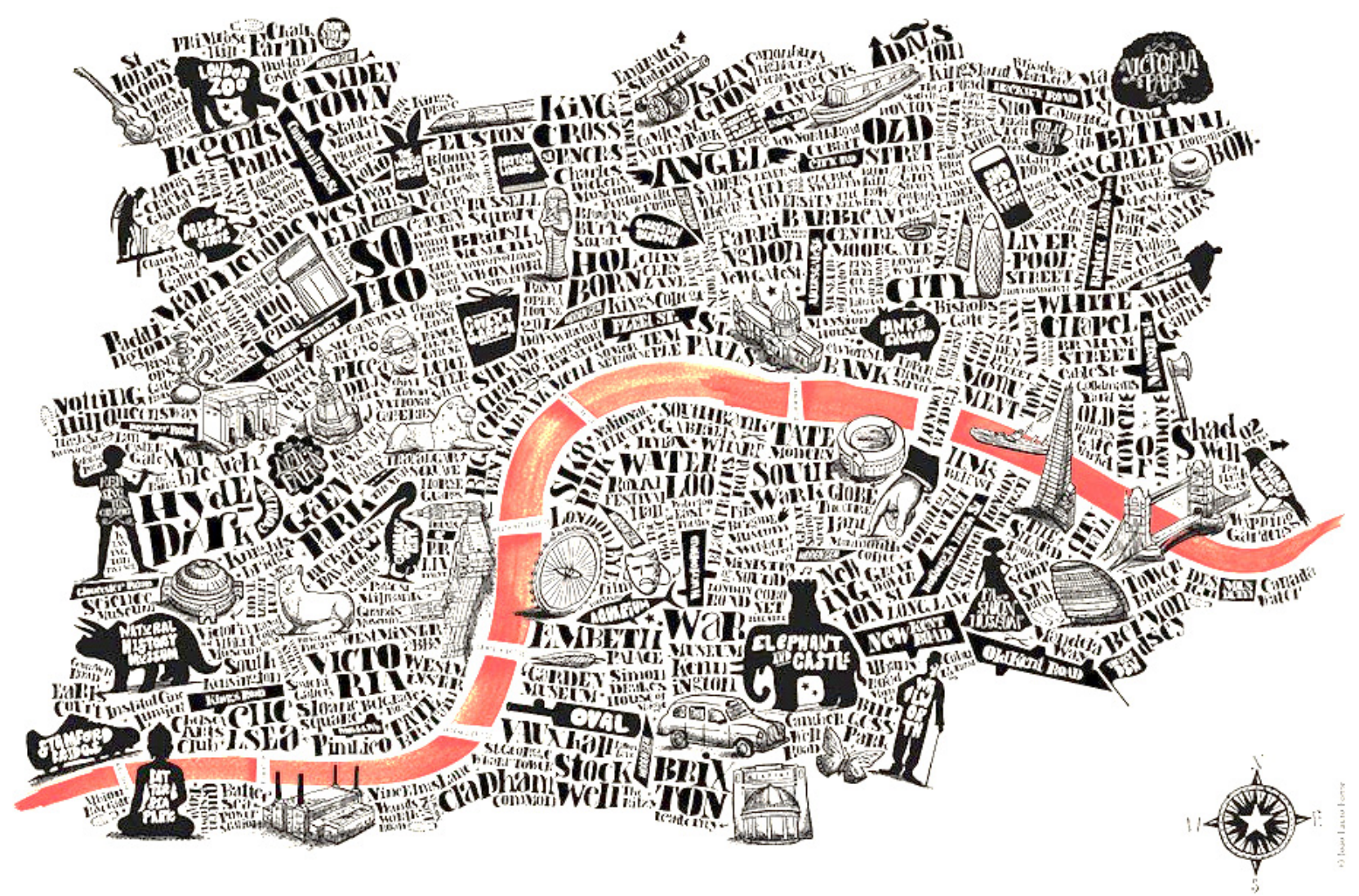

Figure 2. Joao Lauro Fonte, "London Map".

Note: Artist's impression of the various ambiances and thematics encountered around central London along with the most famous landmarks that someone may encounter while walking around the areas displayed. 

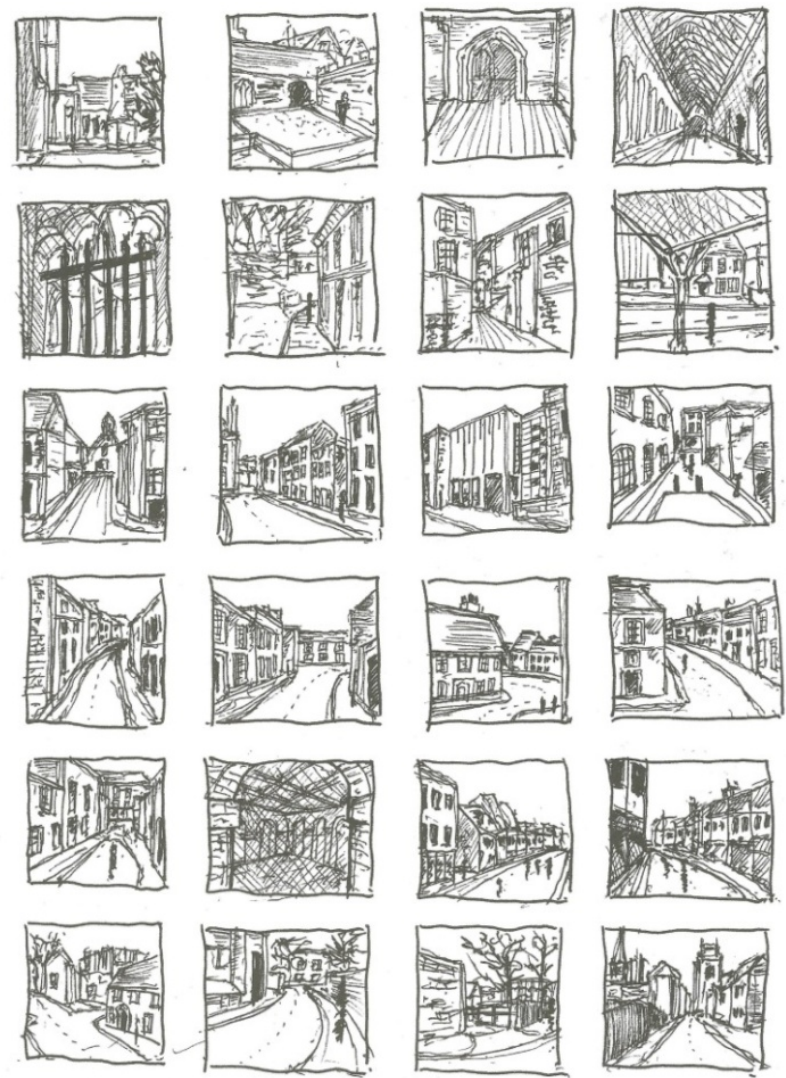

Figure 3. Niall Bird, University of Portsmouth.

Note: Small sketches generated while undertaking a detour can serve as snapshots of the area revealed (from L. Farrelly's Drawing for Urban Design, Laurence King Publishing, 2011, p. 44).
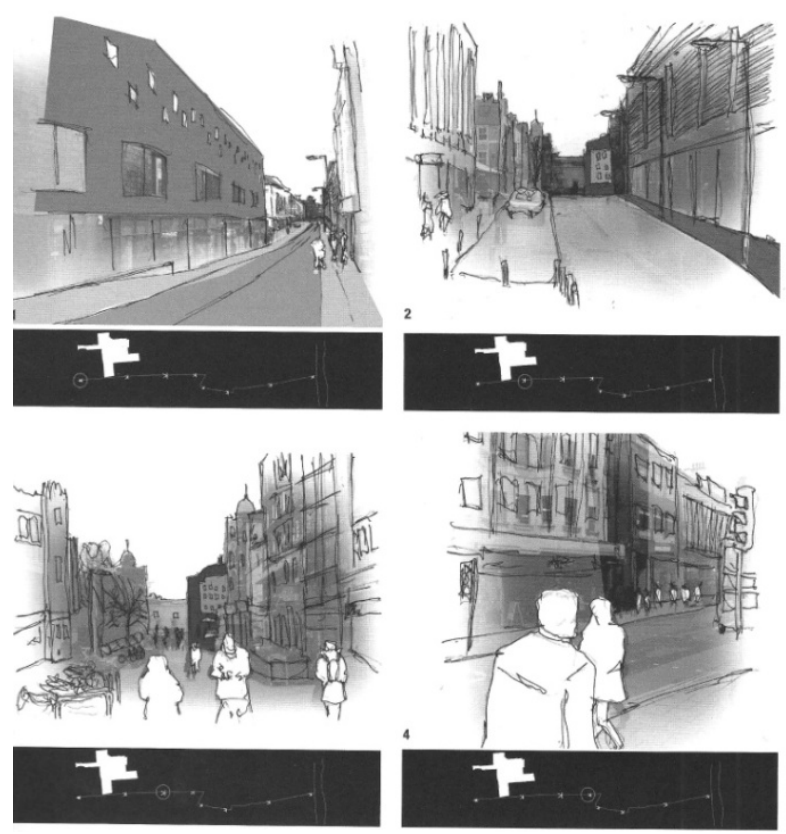

Figure 4. Lee Whiteman, University of Portsmouth.

Notes: Serial views through the city. The route followed is indicated at the bottom of each frame, as a ground plan (from L. Farrelly's Drawing for Urban Design, Laurence King Publishing, 2011, p. 46). 


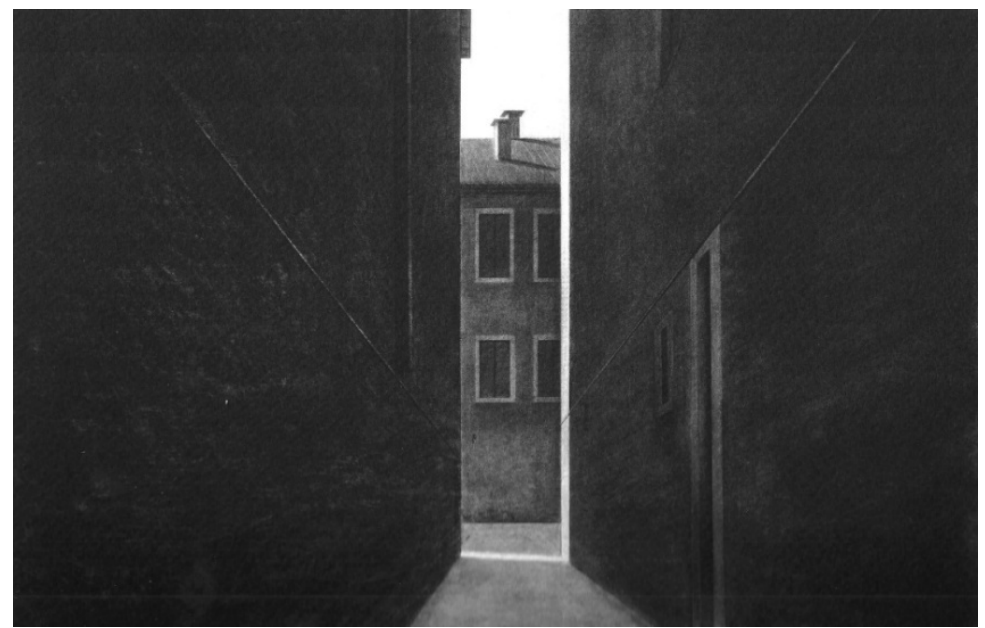

Figure 5. Edward Angeli, "Platz", 2005.

Note: A series of drawings made with pencil and charcoal that act in a similar way to observational sketches produced through a series of routes within the urban environment.

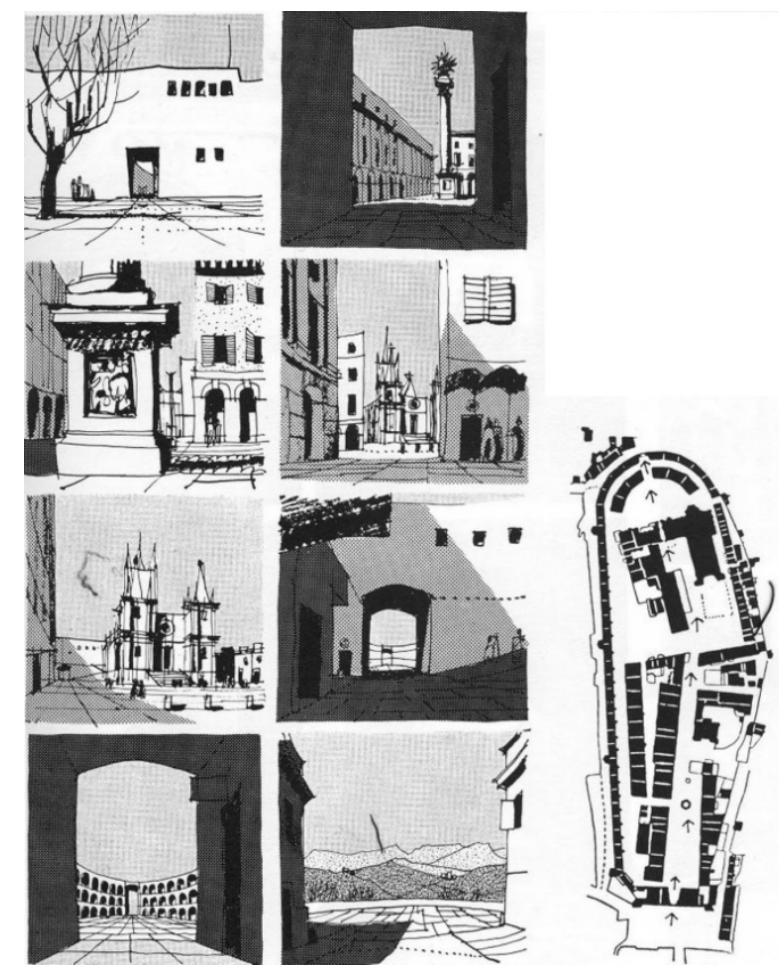

Figure 6. Gordon Cullen, "The Concise Townscape", p. 17.

Note: A series of urban sketches (left) and the main plan that indicates the route followed within the urban environment.

essence of observational sketching is to concentrate on the study of specific aspects of the revealed environment; just like movie frames, the sketches act like snapshots for the area of interest and can thus be used as a data generator. They may focus on the materiality, textures, colours, the use of lights/shadows, edges, routes, boundaries, building types, and various objects encountered on one's dérive. Therefore, a thorough depiction of the study area, the analysis of it, or the comparison with other areas can be achieved. 
Of course, the use of urban photography throughout an urban drift, can equally substitute the practice of sketching as it is a quicker method to record the urban environment and all the concomitant elements that an urban designer/architect/thinker seeks for (see Figure 7).

\section{ARCHITECTURAL/MAPPING PRACTICES: SENSORIAL MAPPING}

"We have trouble representing odours in space, essentially because they are invisible. Only the visual data of architecture can be represented" (Zardini 2005: 303).

The city is a collection of experiences and those elements mentioned before are not always sufficient for a complete and thorough mapping of a city's components. A highly distinctive factor of an area's character can also be the sound and the smell of it. From food markets to public gardens and from industrial areas to harbors and airports, all of them are integral parts of a city which produces an invisible but highly distinctive sensorial aura that can be traced or mapped. These olfactory and audio incentives constitute the smellscape and the soundscape of the city respectively. Sound frequencies and odours become the compass, which can help someone realize whether he is walking through or nearby a food market, a flower garden, a construction site, or a transportation hub (see Figures 8 and 9). The whole process can be practiced, or at least be associated with the notion of urban drifting since the practice principles are based merely on chance encounters and sensorial stimulis.

\section{URBAN DRIFTING IN CONTEMPORARY LITERATURE/VISUAL ARTS}

"The best thing about these walks was that they took you down streets, up alleys, across back gardens, over ditches that you would never normally have visited.
You would discover things: shops, cafés (...) and secret signs" (Drummond 2001).

As Robert McFarlane noticed, the practice of urban wandering allows us to "record the experience as you go, in whatever medium you favour: film, photograph, manuscript, tape (...) Be alert to the happenstance of metaphors, watch for visual rhymes, coincidences, analogies, family resemblances, the changing moods of the street. (...)" (McFarlane 2005). The practice of urban wandering allows us to record the experience and the changing moods of the street as we go, in whatever medium we favour: film, photograph, manuscript, or tape. According to Iain Sinclair, "between the buildings, place is in layers of imperfection, flesh that is attached to the architectural skeleton" ". A number of artists in the field of contemporary visual arts/literature have captured these "imperfections" and dynamics of the city by practicing, either consciously or by chance, the methodological aspects of urban drifting or dérivelflânerie.

In the field of contemporary literature/urban poetry, some of the most interesting contributions have been made by Scottish beat writer, pornographer, and junkie Alexander Trocchi ${ }^{8}$, the French urban poet and filmmaker Georges Perec, South African-born Scottish artist, musician, writer, and record producer Bill Drummond, and of course Iain Sinclair, who is claimed to be one of the most significant figures of modern psychogeography. Trocchi was associated to Guy Debord through their long psychogeographical walks in Paris and his most representative work is his experiential novel Cain's Book (1960) where he described the dark side of NY city through the tales of a drug addict. Georges Perec, in his 1982 novel An Attempt at Exhausting a Place in Paris [Perec (1982) 2010], clearly stated that his intention was to "take note of, that which is not noticed, that which has no importance: what happens when nothing happens other than the weather, people, cars and clouds". In other words, to capture all the happenstance that 


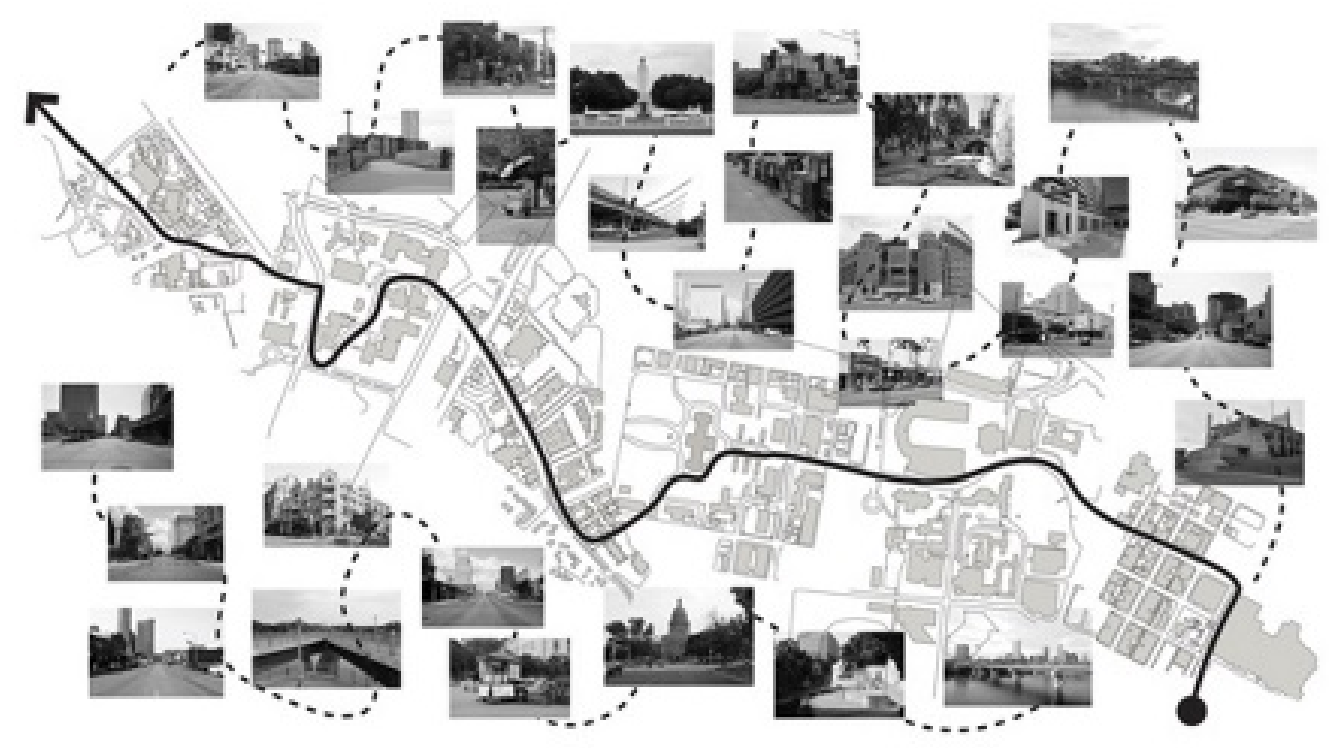

Figure 7. A Sequence of Urban Revelations (Snapshots) Is the Result of This Urban Drifting Study in a Part of Austin, Texas. Medium Used Here Is Photography.

Note: Found at https://www.behance.net/gallery/2032857/The-Aimless-Reader.

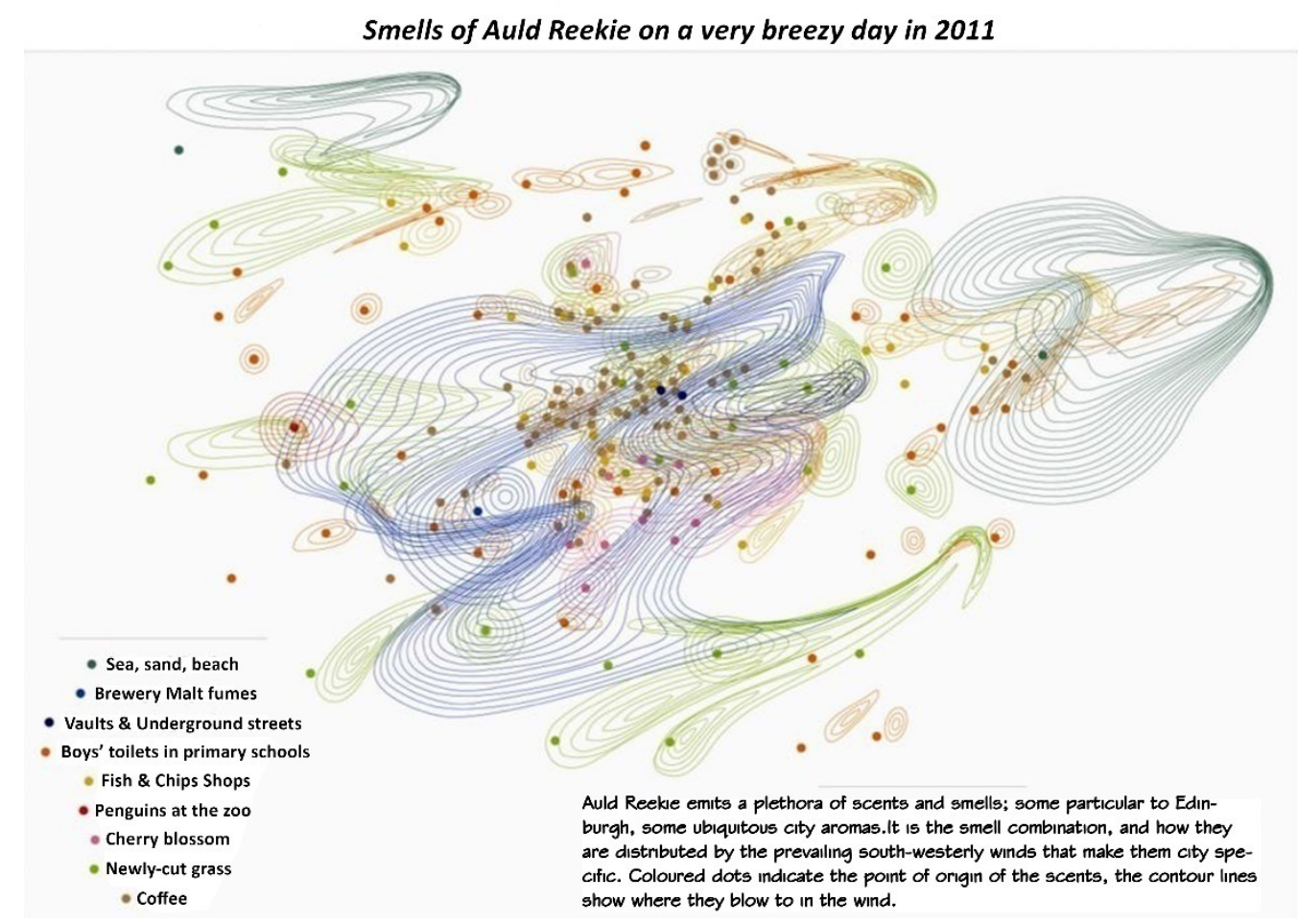

Figure 8. Kate McLean, Smell Map, 2012.

Notes: This unconventional map is a qualitative and quantitative sensorial (olfactory) approach of the specific study area. For the completion of this kind of mapping, the process of urban drifting is essential in order to establish a thorough framework for this area's sensorial charting. 


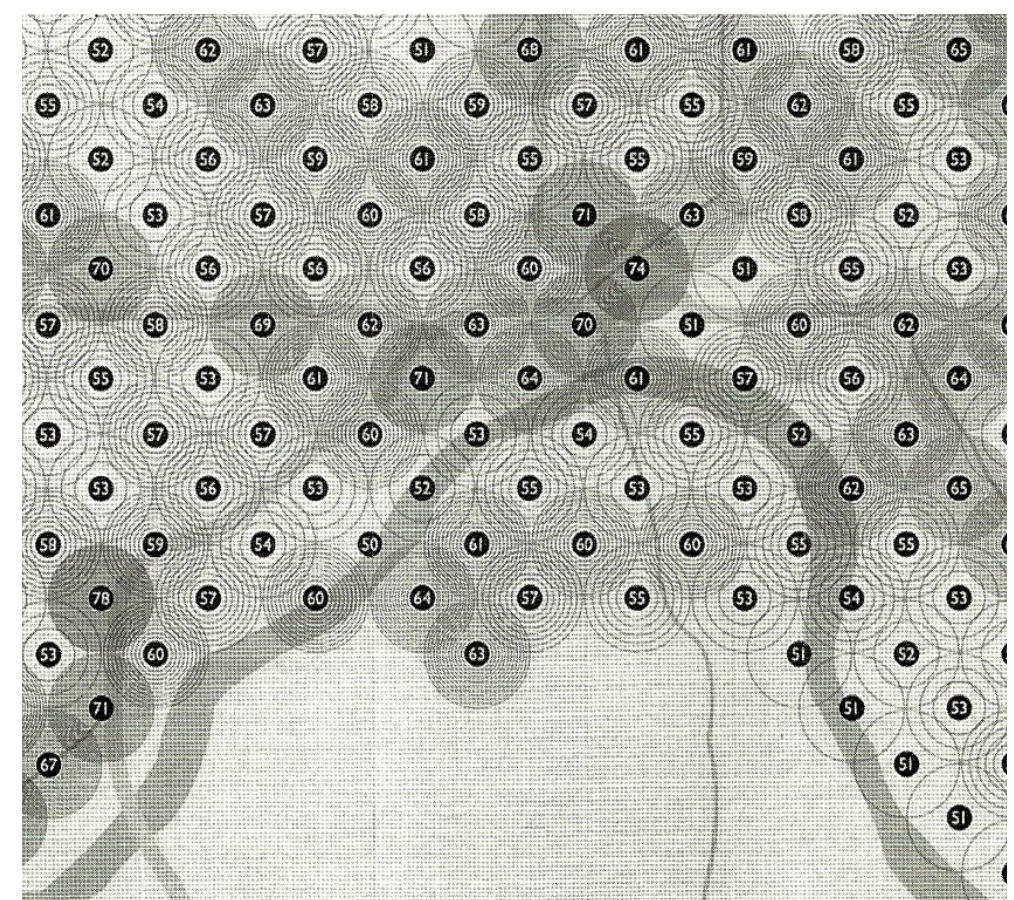

Figure 9. A. Clark, R. Giampietro, R. Hutton, R. Thompson, and J. Zorn: 466 Decibel Readings. Note: A depiction of citywide decibel levels in Minneapolis, University of Minnesota, 2001.

provides Paris with the essence of a unique and intriguing city. Finally, most of Sinclair's works are good examples of modern psychogeographical practices where urban drifting has a protagonist role in his methods of urban encounters. As an example, his 2002 work London Orbital can be mentioned.

One of the most remarkable specimens of urban psychogeographic photography is Ralph Rumney's ${ }^{9}$ "Psychogeographic Map of Venice" (1957, photographic collage) where Rumney created a photographic album of the city while he was stalking American beat author Alan Ansen ${ }^{10}$ (see Figure 10). Another essential example of urban photography is Sophie Calle's ${ }^{11}$ "Suite Venitienne" (1979). Her restless tendencies led her to Venice, where, while stalking random strangers, she recorded parts of the city's physical environment (see Figure 11).

The field of film-making has also contributed significantly in the practices of urban wandering and city contemplation. One thing that cinema offered was to teach us ways of seeing and understanding modern city. To borrow a comment from Lefebvre, "film presents urban space as itself representational, as simultaneously sensory and symbolic" (Donald 2000: 40). One of the most representative films is Patrick Keiller's" "London" (1994). Keiller records the changing faces of contemporary London through his fictional character Robinson and his observational walks-dérives. Keiller, with "London", provides a psychogeographical meditation on London, combining a political response to Thatcherism with an inquiry to the literary history of the city and an ultimate statement on the fate of the modern age flâneur. Other interesting films of similar context are:

(1) "Manhatta", by Paul Strand and Charles Sheeler (1920): A short film about Manhattan, NYC during the eve of the twentieth century. A photographic documentary (in the form of a film) which captures NY's urban environment and aspects of everyday life;

(2) "The Man With the Movie Camera", by Dziga Vertov [USSR (Union of Soviet Socialist Republics), 


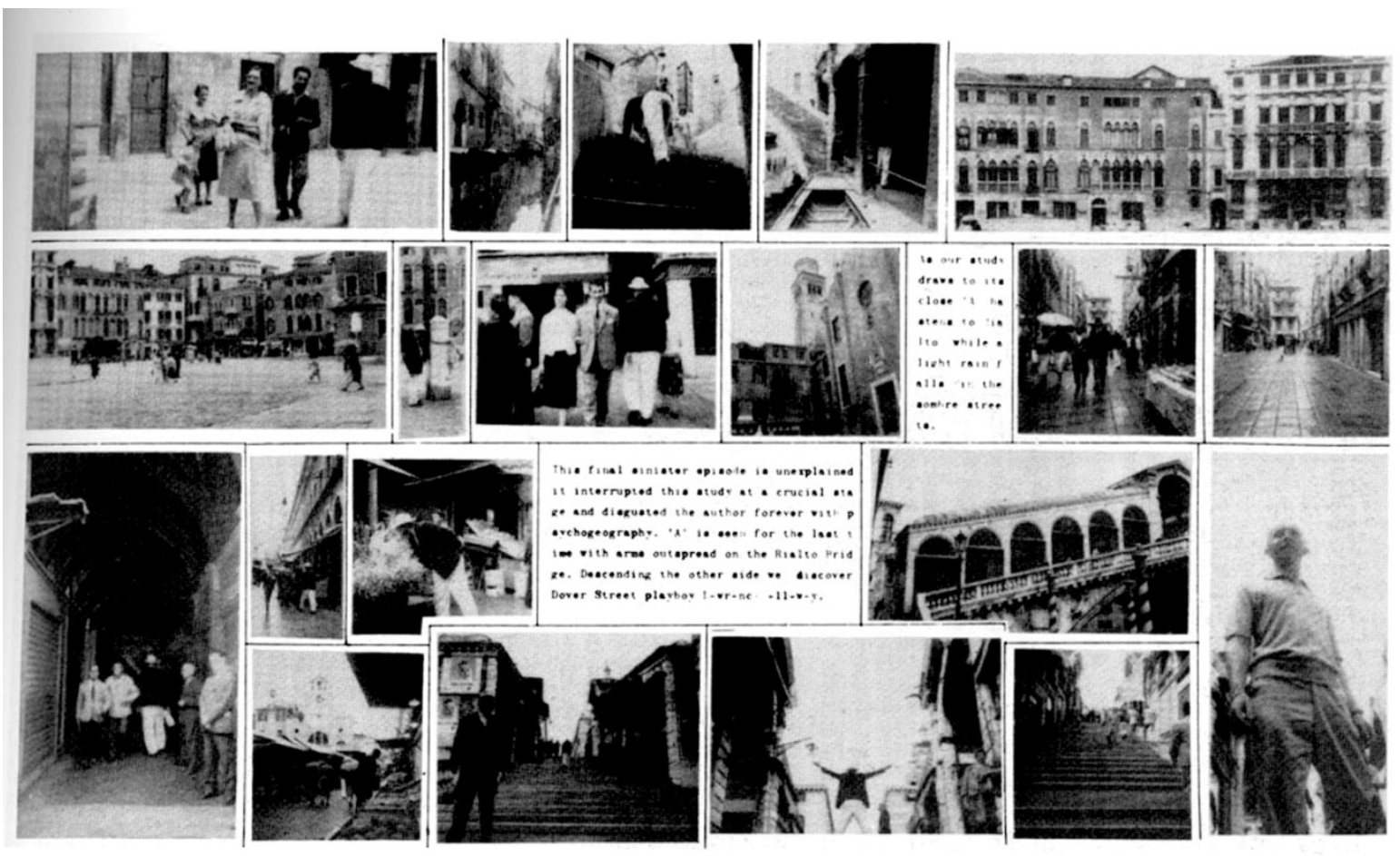

Figure 10. Ralph Rumney, "Psychogeographic Map of Venice” (1957, Photographic Collage).
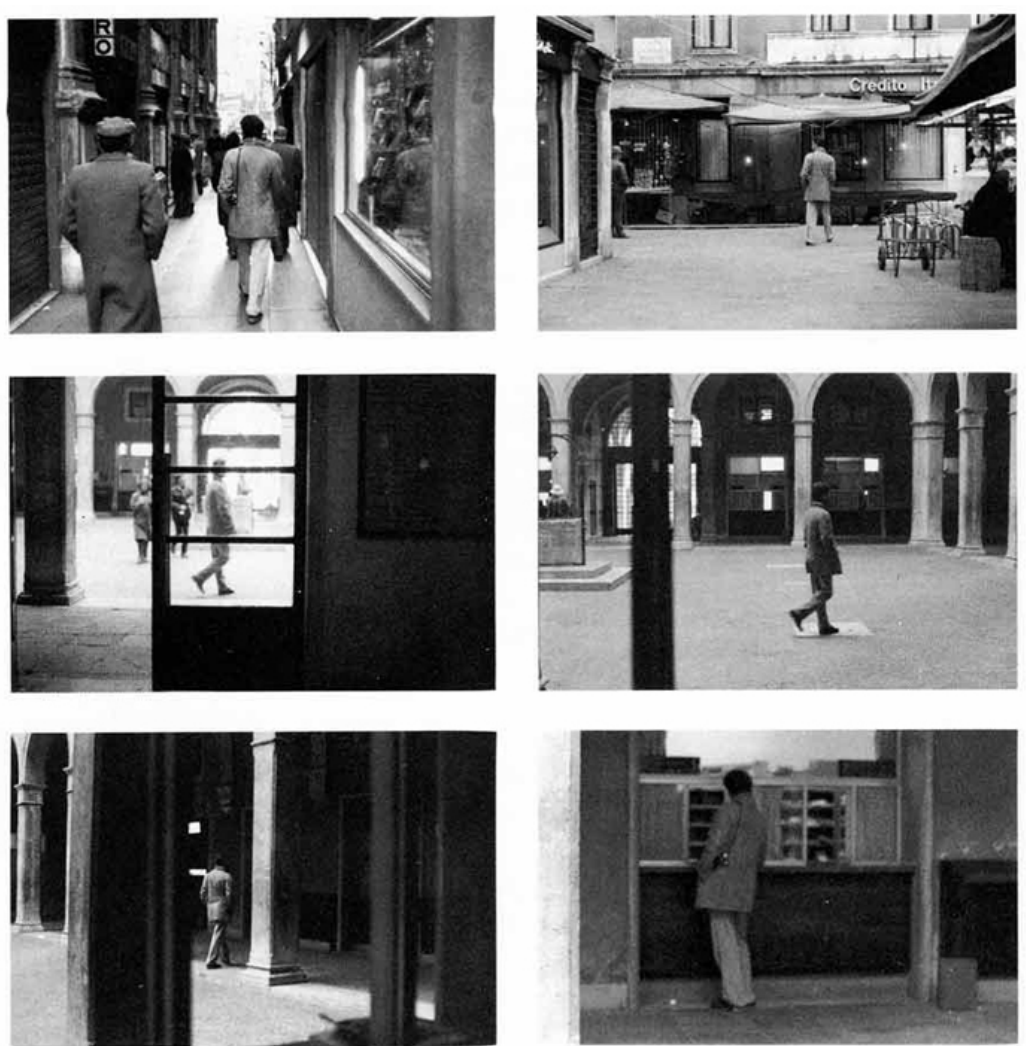

Figure 11. Sophie Calle, "Suite Venitienne" (1979, Photography). 
1929]: A movie about urban life in early twentieth century Soviet Union, captured by the camera of an efficient cinematographist and urban stroller;

(3) "The Naked City", by Jules Dassin (1948): A crime/detective story which is set in NYC. Apart from the detective nature of the plot, the viewer is introduced to the urban life of NY through citizen's daily working routine.

\section{CONCLUSIONS}

"The act of walking is to the urban system what the speech act is to language or to the statements uttered. (...) it is a process of appropriation of the topographical system on the part of the pedestrian (just as the speaker appropriates and takes on the language)" (De Certeau 1984: 97).

The pedestrian in the contemporary capitalist city has become a subordinate to the dictatorship of the automobile, the spectacle, and consumerism. He is confined in an emerging new urban landscape, a non-place devoid of individuality and content while dominated by technological amenities and billboards. Situationists' goal was to resist and overthrow the "society of the spectacle", the immense banalization and homogenization of modern society. Their goal is significantly topical in our present times where the losses of quality public space and the ongoing immense privatization of our cities are even more apparent.

By establishing urban drifting as a spatial practice, we can raise awareness on crucial aspects of our urban sphere like:

(1) How the built environment impacts on the aesthetics of everyday life and our psychology;

(2) Realize and resist the encroachment of private pseudo-public space into public;

(3) Map the layered history of our streets and neighbourhoods;

(4) A potential improvement of our living-working space by the collaboration of psychogeographers and urban planners/architects;

(5) And most importantly, escalate our bodies into "vessels of protest" by using them to appropriate urban space and practice our right to the city.

The activity of urban drifting is a radical act, a denouncement of modern urban life which lacks in passion and originality; a spatial practice that can discover and preserve collective memory and identity over the threatening homogenization of urban space, and therefore an oblivious and submissive existence. A city has always contained more situations and qualities than any inhabitant can know, which can be best experienced by walking. As Rebecca Solnit has claimed, a citizen's love for his/her city has passionately merged with the lust of a man for a passer-by (Solnit 2000: 20). And this merging is integrated on the streets and on foot. "Walking has become sex!" (Solnit 2000: 20).

\section{APPENDIX}

Practices of Urban Drifting: A Study Case

Aristotelous pedestrian walkway, Thessaloniki, Greece: Mapping the inconspicuous

Independent project, first semester, MA in Architectural and Urban Design, University of Brighton (2014).

The project:

The main subject of this project is to examine, analyse, and map a public space of free choice in terms of qualitative and quantitative appropriation of it by the public. My study case is one of the most significant and famous open spaces in my hometown, Thessaloniki. The diversity of its users, textures, paths, edges, and sensory stimulis constitutes Aristotelous Square a challenging case for recording and mapping all those elements (physical, psychological, or sensorial) that establish Aristotelous Square as a public space of certain ambiance, utility, and significance for the citizens. 
Aims:

One of the biggest challenges during the development of this project was to determine Aristotelous" character and "detect" all the factors that render the area a desired public space in the heart of the city. In order to achieve that, a more spherical and integrated perspective of Aristotelous was essential. This fact consequently led to the realization that a qualitative assessment of a public space must not only confine in its physical appearance, hence the design elements, but it should also estimate the ambiance and various sensory incentives that attract or repel the public from it. Aristotelous Square, in terms of physical appearance, is an elongate pedestrian walkway of predominantly commercial and leisure use (cafes, restaurants, and bars). However, the locals when referring to it, tend to include a wider area developed on both sides of the axis, comprised by multiple spaces of different ambiance and use. The strong and clearly signified edges of Aristotelous walkway are "penetrated" by multiple vertical streets and avenues throughout its development until the waterfront, opening up further options for detours alongside the apparent route.

\section{Methodology/Observations:}

For a more comprehensive recording, I divided the study area into several sub-areas so that it can be studied individually as areas of different use, human density (primary recordings) and ambiance (secondary recordings). For each of the study areas, I practiced the activity of urban drifting, meaning that I excluded any predefined plan or destination from my itinerary and thus, let the crowd and my sensorial incentives guide me through. Most of my recordings were done by using photography, sound device, and hand notes while others were achieved by being one with the crowd, observing and/or videotaping behaviours, street choreographies, and other "peculiar" situations that are less likely to be experienced on conventional routes. On every sub-area, I established certain static points of observation which in any case did not exceed the time limit of five minutes (see Figure A1). Throughout the recordings, I focused on the quality of sounds and odours as well as their context in terms of land uses (commercial, leisure, etc.). This methodological framework was repeated one more time on a different day in order to record any occurring fluctuations and develop the average data.

My primary observations were confined exclusively on Aristotelous walkway. Across the vertical axis (points 4 and 9 with the intermediate area included), the recordings do not vary in any significant way, as the major land uses are commercial stores and numerous cafes. The continuous perspective allows the user to anticipate or see any potential changes or obstacles along his course, thus excluding any revelations along the way or chance encounters with various situations that could potentially alter the spatial perception of the viewer/walker. The soundscape does not display any significant fluctuations and the noise levels remain on an average level (between 60 and $70 \mathrm{~dB}$ - see also Figure F6) with the exception of the crossroads, where the sound levels increase dramatically due to car traffic.

However, the scenery changes completely within the sub-areas A, B, and C (on the left flank of the Aristotelous walkway) as we have a great variety of land uses, odours, sounds, and anthropogeography. Furthermore, the numerous narrow alleys within those sub-areas limit the perspective, establishing an ambiance of "urban disclosure" or "emerging view" [Cullen (1961) 1971: 9]. The areas around observation points 1, 2, 3, and 5 have a strong retail character (neighbourhood level mercantile activities) as well as a number of small restaurants - tavern (point 2). The drifter is "absorbed" by the crowd and gets the sense of a ritualistic process, as he drifts through the numerous alleys and traditional trade arcades (observation point no. 5). The predominant land uses are small retail shops with food products (see Figure E5) and occasionally small old clothing firms. The old architectural fabric reveals the historic importance of 
the area and emphasises the retail ambiance of it. The noise levels are significantly high and the smellscape displays a great variation as the observer is exposed to different smells, from fresh fish to flowers and spices.

The scenery keeps changing as someone descends toward the waterfront (points 12, 13). While the walkway does display a more homogenized and insignificant character of little variations, the coterminous sub-areas C (right flank of the walkway) and $\mathrm{D}$ reveal a different landscape of predominantly commercial character. A certain ambiance of consumerism and privatization prevails as the walker is exposed to the numerous billboards and displays of popular fashion stores. Points 8 and 10 are typical examples of guarded semi-public, commercial enclaves with the provision of other amenities, like famous restaurants and cinema complexes.

The anthropogeography also changes in a noticeable way, as no homeless or beggars are encountered within this sub-area. Instead, the majority of the passers-by are either hasty commuters or mid/high class citizens doing their shopping or just browsing. The soundscape does not display any significant fluctuations apart from the steady noise caused by the immense levels of traffic (one of the most busy avenues cut through the walkway), occasionally interrupted by street vendors or other clamorous activities (e.g. busking and demonstrations). The smellscape, on the other hand, is really interesting on that specific point as someone might encounter the mesmerizing aroma of various perfume parlours or the "addictive" smell of a famous bakery chain that dominates one of Aristotelous Square's corners. Furthermore, another variable alters significantly the smellscape and that is the bad odour that comes from the harbour. I used the term "variable" as this "trademark" smell depends each time on the wind's direction.

Finally, the drifter inevitably ends up to Aristotelous Square. An entirely different scenery introduces the notion of open view to the port and the sea while on each of the square's sides there are a number of "glamorous" restaurants, bars, and clubs. At this point, an interesting phenomenon occurs regarding the anthropogeography and appropriation of space. The sides of the square (colonnades) are highly crowded with people enjoying their coffee or lunch/dinner, creating a "suffocating" and rather disturbing image of dramatic human density while the main square remains less occupied and gives the impression that acts more like a transitional point rather than a focal one. According to William $\mathrm{H}$. Whyte and his perspective on urban spaces' social life (documentary, 1979), people tend to concentrate on the edges and, preferably where other people are. Aristotelous Square triumphantly confirms this ascertainment by its distribution of human factor among its space. Furthermore, less privileged people and/or immigrant populations express a preference to the centric space of the square and its underdeveloped public sitting points, thus creating a contradictory image of two different types of occupants of the same space.

\section{Conclusions}

Those brief walks (drifts) led me to investigate the reasons why people are drawn or repelled by a space. Focusing on the happenstance and potential patterns or rhythms generated among the crowd by observing and being part of it, I intended to interpret the demography of the place, the quality, quantity, and topography of social encounters (where they happen and why) and any additional factors that functioned - or could function-as "hoovers" for the public flow. Throughout my drifts, a wide range of emotions were generated, which happened to vary every time I was crossing through the diverse ambiances of Aristotelous. A significant navigation tool was my sense organs, especially those emphasizing the peculiarity of something that can be heard or smelled but not seen. One situation led to another and then I realized that I was enhanced with a spherical view of the place and its features, at a level that I could chart certain aspects of the public realm (see figures below). 


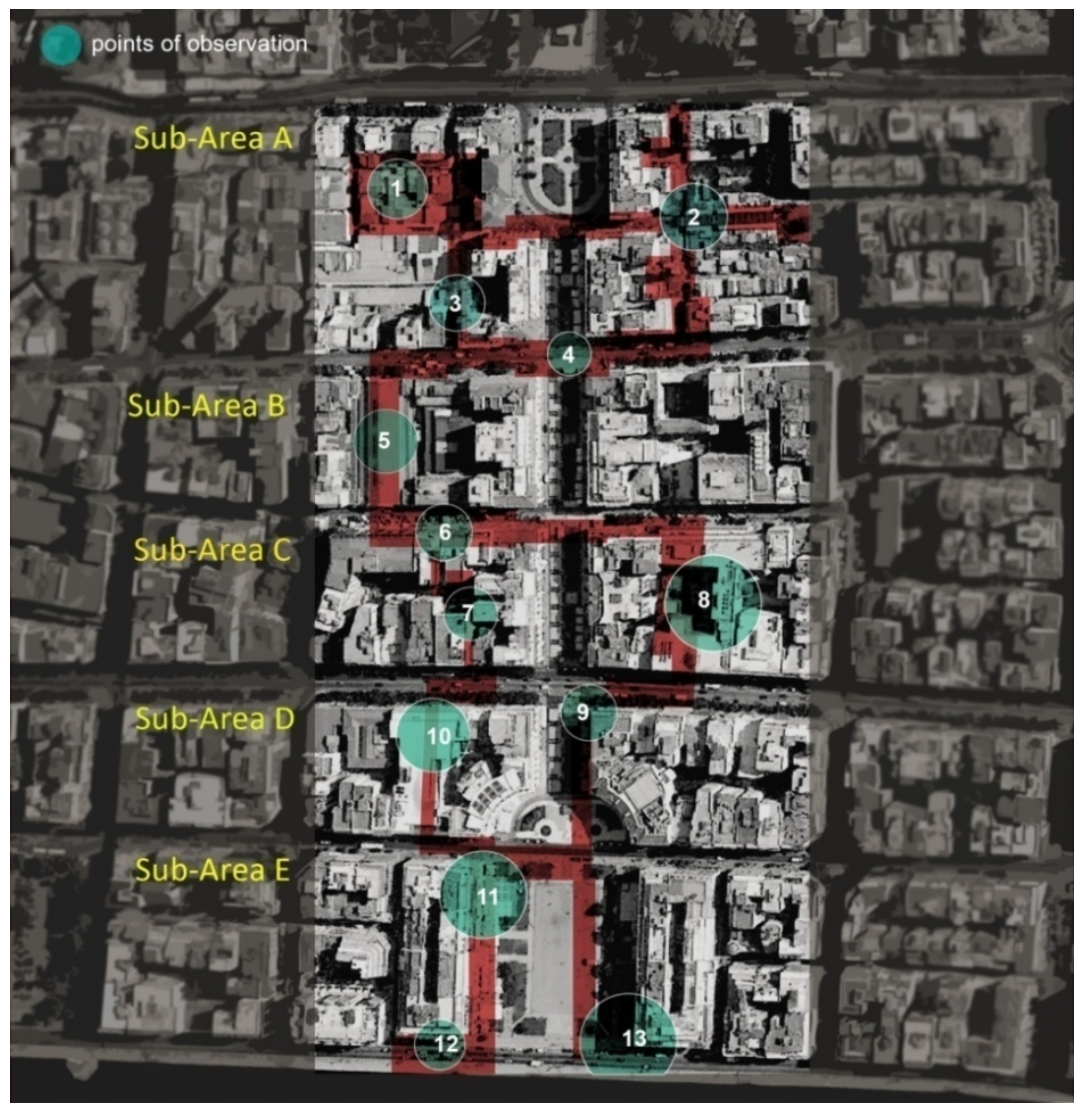

Figure A1. Aristotelous' Public Walkway and Square and the Chance Courses That Were Undertaken Throughout Its Surroundings.
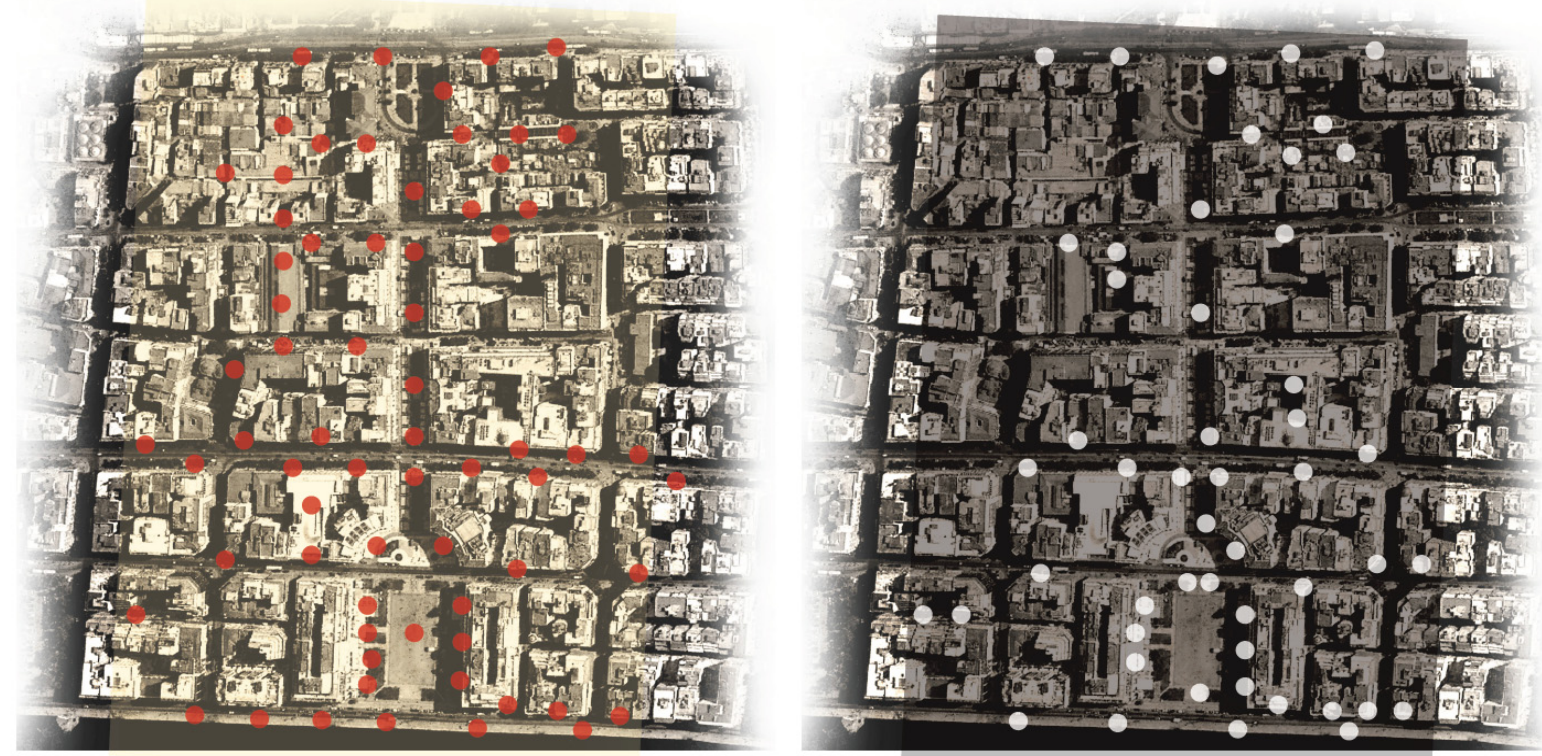

Figure B2. These Maps Visualize the Most Frequently Used Points by People During Daytime (Left) and Night-Time (Right). The Observations Were Taken Between 11:00 and 14:00 and 21:00 and 24:00 Respectively. 

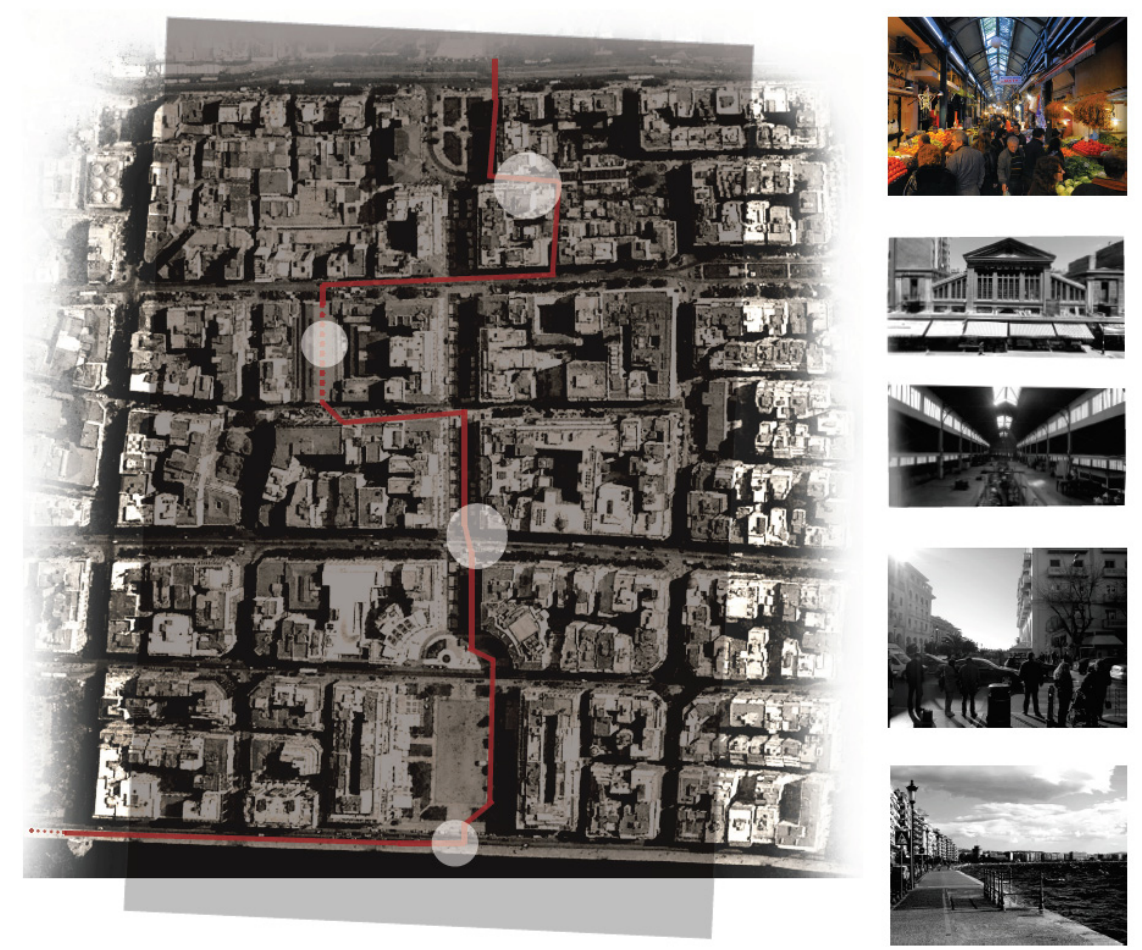

Figure C3. An Indicative Observational Detour Followed Within the Case Study Area and the Revealed Environment Along the Route.

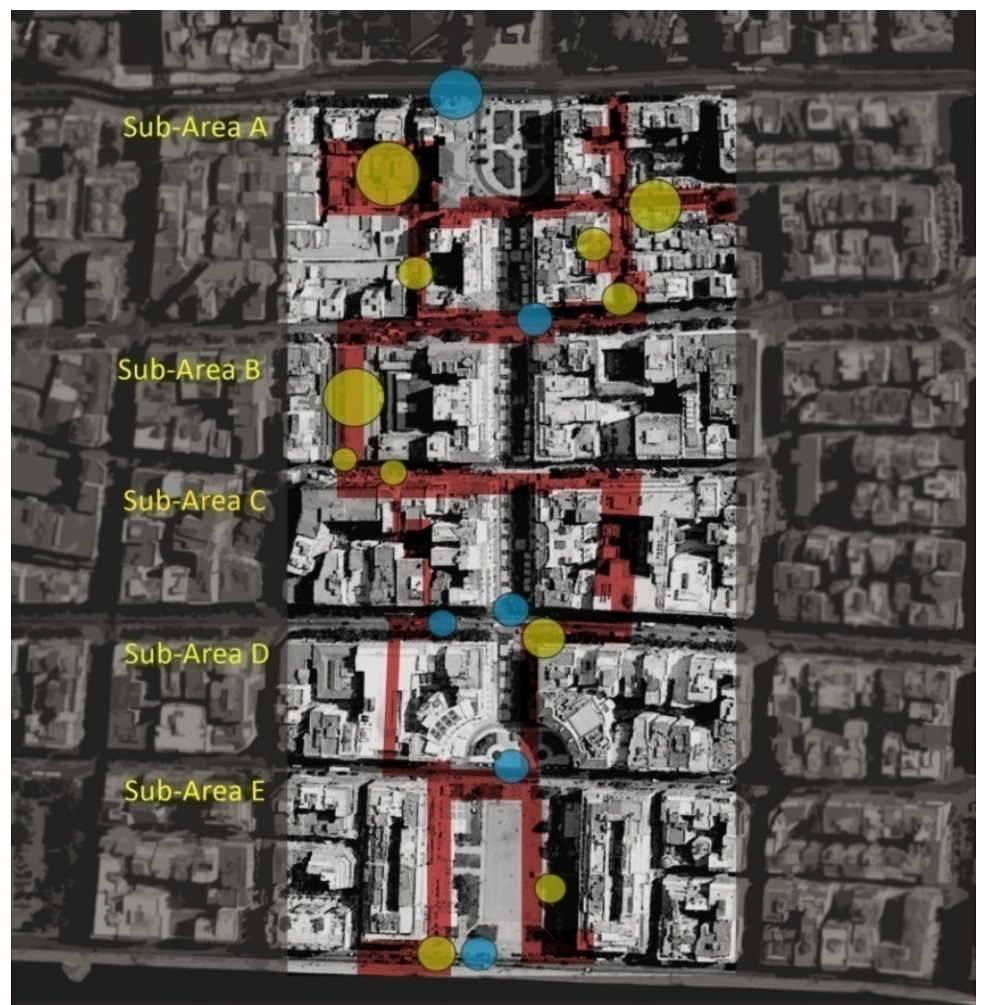

Figure D4. This Image Displays the Points of Distinctive Odours. The Yellow Circles Represent Food-Originated Smells and the Blue of Various Nature, Usually Disturbing. 

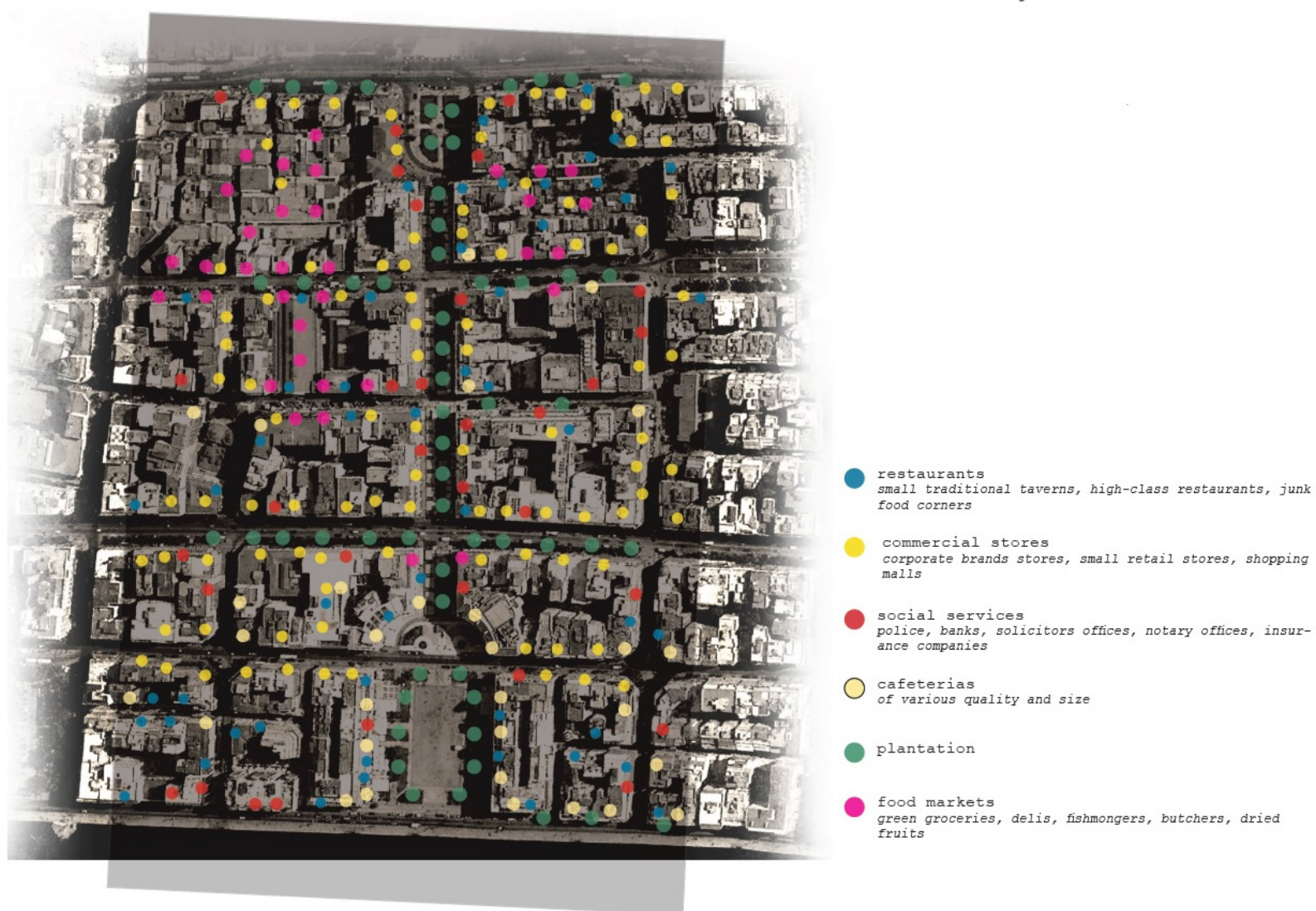

Figure E5. This Image Depicts the Land Uses Within and Around Aristotelous Pedestrian Walkway.

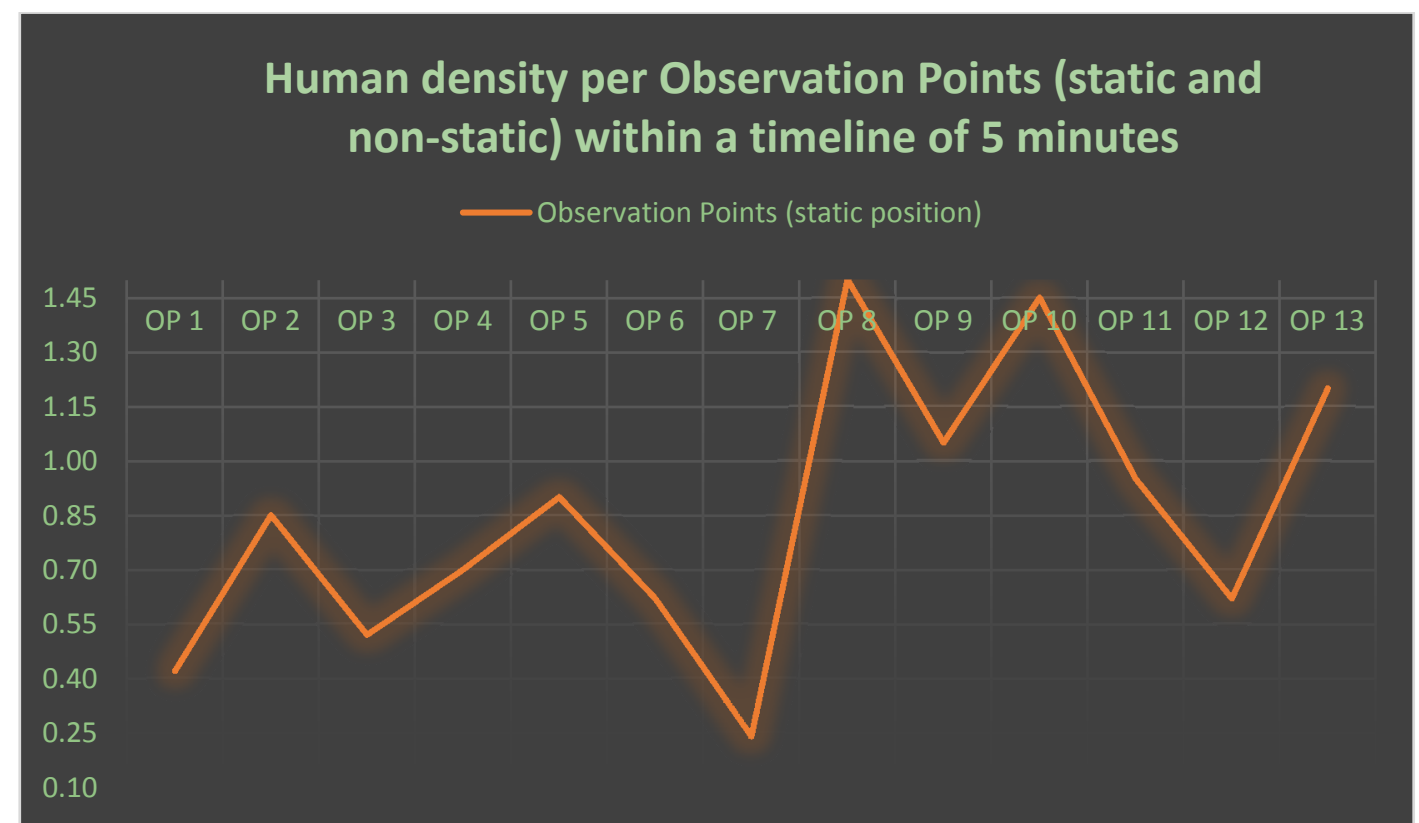

Figure F6. This Indicative Chart Displays the Levels of Human Concetration Among Aristotelous' Urban Public/Semi-public Spaces. These Data Are Generated by the Number of Individuals Counted in a Timeline of 5' and Within a Zone of 10 Meters From the Observation Point. Observations Were Made on Two Weekdays Between 11 am and 2 pm With Good Weather Conditions. This Is the Average Rate. 
Varying in smells, sounds, patterns of movement, and points suitable for sitting on, Aristotelous is an "urban canvas" teeming with possibilities and situations, most easily experienced by drifting about. A designated, public space that should not be conceived as such simply by its individual phenomenality but also by the psychological and emotional "aura" that its coterminous surroundings emit upon it. If we were to exclude Aristotelous' sub-areas, then the result would be just a long, relatively well developed pedestrian walkway that does not differ significantly from other public spaces. Therefore its desirability relies on the fact that it is a public space that successfully interwovens the various networks of social life developed within and around it, rendering it a vivid and diverse public space.

\section{Notes}

1. The term flâneur is generally associated with a masculine practice. For further details about the flâneusse and the gender division, you may refer to D'Souza A. and T. McDonough, eds. 2008. The Invisible Flâneusse?: Gender, Public Space and Visual Culture in Nineteenth Century Paris. Manchester University Press.

2. Hessel, F. 1929. "Spazieren in Berlin.” Anecdotal essays.

3. Stevenson, R. L. "Jekyll and Hyde.” P. 23.

4. Internationale Situationiste \#1.

5. Stewart Home, Mind Invaders.

6. Richardson, T. "My Name Is Tina and I'm a Psychogeographer: Situating the Addictions and Abuses of Urban Walking Today."

7. Iain Sinclair in conversation with J. Meades, Oxford Brookes University, March 2013.

8. July 30, 1925-April 15, 1984.

9. Ralph Rumney (June 5, 1934-March 6, 2002): English artist who lived most of his life as a wanderer. Co-founder of London Psychogeographical Association.

10. Alan Ansen (January 23, 1922-November 12, 2006) was an American poet, playwright, and associate of Beat Generation writers.

11. Sophie Calle (born in 1953) is a French writer, photographer, installation and conceptual artist.

12. Patrick Keiller (born in 1950) is a British architect, film-maker, writer, and lecturer.

\section{References}

Baudelaire, C. 1964. The Painter of Modern Life. New York: Da Capo Press.

Boyer, C. 1995. "Twice-Told Stories: The Double Erasure of Times Square." Pp. 77-81 in Strangely Familiar: Narratives of Architecture in the City, edited by I. Borden, J. Kerr, A. Pivaro, and J. Rendell. London: Routledge.

Campbell, K. and R. Cowan, eds. 2016. The Radical Incrementalist: How to Build Urban Society in 12 Lessons. England: Massive Small.

Chtcheglov, I. 1953. "Formulaire pour un urbanisme nouveau" (Formulary for a New Urbanism). Internationale Situationniste \#1, Paris, June 1958.

Coverley, M. 2010. Psychogeography. England: Pocket Essentials.

Cullen, G. (1961) 1971. The Concise Townscape. New York: Architectural Press.

Danchev, A. 2011. 100 Artists' Manifestos: From the Futurists to the Stuckists. London: Penguin Classics.

De Certeau, M. 1984. The Practice of Everyday Life. USA: University of California Press.

De Quincey, T. 1997. Confessions of an English Opium Eater. London: Penguin.

Donald, J. 2000. "Cinema.” P. 40 in City A-Z, edited by S. Pile and N. Thrift. UK: Routldege.

Drummond, B. 2001. 45. UK: Abacus Publications.

Farrelly, L. 2011. Drawing for Urban Design. London: Laurence King Publishing.

Frisby, D. 2001. Cityscapes of Modernity. UK: Polity Press.

Hart, J. 2004. A New Way of Walking. Retrieved (http://www.utne.com/community/a-new-way-of-walking).

Kerr, J. and A. Gibson, eds. (2003) 2012. London: From Punk to Blair. UK: Reaktion Books.

Lynch, K. 1960. The Image of the City. USA: MIT Press.

Lynell, G. 2015. "Visions and Revisions: The Spirits of Los Angeles." Boat Magazine, \#8, p. 19.

McFarlane, R. 2005. “A Road of One's Own.” Times Literary Supplement. Retrieved October 7 (http://www.thetimes.co. uk/tto/others/article1888693.ece).

Perec, G. (1982) 2010. An Attempt at Exhausting a Place in Paris. USA: Wakefield Press.

Pile, S. and N. Thrift, eds. 2000. City A-Z. UK, USA: Routledge.

Sadler, S. 1998. The Situationist City. USA: MIT Press. 
Saltz, J. 2008. "Modern Machinery.” New York Magazine. Retrieved September 7 (http://nymag.com/news/intelligen cer/49958/).

Solnit, R. 2000. Wanderlust: A History of Walking. USA: Penguin Books.

Zardini, M., ed. 2005. Sense of the City: An Alternate Approach to Urbanism. CCA, Montreal, Canada: Lars Müller Publishers.

\section{Bio}

Alexandros Daniilidis, MSc in Architectural Engineering from Democritus University of Thrace, Greece, MA in Architectural and Urban Design from the University of Brighton, UK; research fields: urban cultures from the sociological point of view as well as the comprehensive design of public urban space and its effects on citizen's emotional and physical behaviour. 